\title{
Association Between Gastrointestinal Events and Persistence with 0steoporosis Therapy: Analysis of Administrative Claims of a U.S. Managed Care Population
}

\author{
Ankita Modi, PhD; E. S. Siris, MD; Xiaoqin Yang, PhD; Chun-Po Steve Fan, PhD; and Shiva Sajjan, PhD
}

\begin{abstract}
BACKGROUND: A large proportion of patients do not persist with osteoporosis (OP) therapy. Gastrointestinal (GI) events (e.g., gastroesophageal reflux disease and nausea/vomiting) are common among OP patients receiving OP therapy and may impact persistence with treatment.

OBJECTIVE: To examine the association of GI events and persistence with OP therapy.

METHODS: Using a large U.S. administrative claims database, we studied women aged $\geq 55$ years who received oral bisphosphonate (BIS) as their first OP therapy from 2002-2009. The index date was the first pharmacy claim date recorded for oral BIS therapy; the baseline period was 12 months pre-index, and follow-up was 12 months post-index. Patients were considered persistent with therapy if they had continuous refills of the index drug class without additional drug therapy from a different drug class from the index date until the end of the follow-up period with no gaps in supply greater than $\mathbf{4 5}$ days. Discontinuation was defined as the first gap greater than 45 days during which there was no evidence of refills of $O P$ medication. The association between post-treatment Gl events and the risk of discontinuation or switching was modeled with Cox regression stratified by presence of baseline GI events and adjusted for baseline clinical and demographic characteristics.
\end{abstract}

RESULTS: Of the 75,593 women who met eligibility criteria, $59.9 \%$ discontinued BIS; $39.3 \%$ were persistent; and $0.5 \%$ switched to non-BIS. GI events were diagnosed in 20,073 patients $(26.6 \%)$ during baseline and in $21,142(28.0 \%)$ in the post-treatment period (12-month follow-up postindex). Patients with post-treatment GI diagnosis were $35.6 \%$ more likely to discontinue or switch treatment ( $\mathrm{HR}=1.356,95 \% \mathrm{Cl}=1.318-1.396)$ during the 12-month follow-up compared with those without post-treatment GI diagnosis. Gl events that occurred closer to treatment discontinuation or switching were associated with a greater risk of discontinuation or switching: $37.9 \%(\mathrm{HR}=1.379,95 \% \mathrm{Cl}=1.338-1.421)$ for $\mathrm{Gl}$ events within 6 months of discontinuation or switching and $45.6 \%(\mathrm{HR}=1.456,95 \% \mathrm{Cl}=1.408-1.505)$ for GI events within 3 months of discontinuation or switching.

CONCLUSIONS: Among women aged 55 years or older in a U.S. managed care population, post-treatment GI events were associated with a higher risk of discontinuation of oral BIS or switching to non-BIS.

J Manag Care Spec Pharm. 2015;21(6):499-506

Copyright $\odot 2015$, Academy of Managed Care Pharmacy. All rights reserved.

\section{What is already known about this subject}

Osteoporosis treatment significantly decreases the risk of fragility fracture. However, many patients do not persist with osteoporosis therapy long enough to gain the protective benefits of therapy. Gastrointestinal symptoms have been linked with osteoporosis therapy discontinuation in clinical practice.

\section{What this study adds}

This study evaluated the association between post-treatment gastrointestinal events and treatment discontinuation and switching patterns among women during the first year of oral bisphosphonate treatment

Following initiation of oral bisphosphonate therapy, women who experienced gastrointestinal events were 36\% more likely to discontinue therapy or switch to nonbisphosphonates than women who did not experience gastrointestinal events while on therapy.

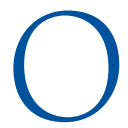
steoporosis is a disease characterized by reduced bone mineral density and deterioration of bone microarchitecture. In the United States, there are an estimated 10 million people who have osteoporosis, and an additional 43 million have low bone density. ${ }^{1}$ By 2020 , it is expected that half of all Americans over 50 will be diagnosed with osteoporosis or develop clinically significant low bone density. ${ }^{2}$

Pharmacotherapy is recommended for patients diagnosed with osteoporosis and those at high risk for fragility fractures. ${ }^{3}$ The U.S. Food and Drug Administration had approved several agents for the treatment of osteoporosis, including bisphosphonates (e.g., alendronate, risedronate, ibandronate, and zoledronic acid); calcitonin; selective estrogen receptor modulators (e.g., raloxifene); parathyroid hormone (e.g., teriparatide); and the receptor activator of nuclear factor-kappa B ligand (RANKL) inhibitor (denosumab) during the 2002-2010 time frame. Among osteoporosis treatments, oral bisphosphonates are currently considered the first-line treatment option, with more than 150 million bisphosphonate prescriptions dispensed from 2005-2009 in the United States alone. ${ }^{4}$

However, suboptimal compliance and low persistence to osteoporosis medication pose significant challenges for reducing the risk of fragility fracture. ${ }^{5,6}$ Even though medication compliance is strongly linked to reduction in fracture risk, ${ }^{7-11}$ several studies have indicated that compliance with osteoporosis medication is suboptimal as evidenced by a medication possession ratio less than $0.8 \cdot{ }^{12-14}$ Additionally, many patients started on osteoporosis medication do not persist with treatment. ${ }^{9,10,15-17}$ Approximately 50\% or more of patients newly started on bisphosphonates discontinue treatment within 12 
months of initiation and, as a consequence, experience significantly higher risk of fracture compared with persistent patients. ${ }^{15,18-23}$

Multiple studies indicate that medication side effects may be one of the key factors influencing patients' suboptimal treatment persistence and adherence behavior. ${ }^{24-26}$ Gastrointestinal (GI) events are common among patients receiving bisphosphonate therapy for the treatment of osteoporosis. GI events may significantly affect medication tolerability. Woo et al. (2010) recently conducted a prospective analysis that concluded that having any GI events at study entry was associated with increased therapy discontinuation. ${ }^{27}$ However, there is limited evidence examining the association between GI events and treatment persistence within a managed care setting in the United States.

The purpose of this study was to estimate the proportion of patients with GI events post-treatment initiation and examine the association between GI events and osteoporosis treatment persistence in a U.S. managed care population.

\section{Methods}

\section{Design and Data Source}

The retrospective cohort study was conducted using the i3 InVision Data Mart (now the Optum Clinformatics Data Mart). This large, national U.S. claims database contains de-identified patient information, including demographic characteristics and medical and pharmacy claims data. Medical claims include International Classification of Diseases, Ninth Revision, Clinical Modification (ICD-9-CM) diagnosis and procedures codes. The outpatient pharmacy claims data contain National Drug Code numbers for dispensed medications. Over 3 million patients with a diagnosis of osteoporosis, osteoporosis-related fracture, and/or a prescription for a medication used to treat or prevent osteoporosis were included in the database during the study period from January 2001 through December 2010.

\section{Sample Selection}

Women aged 55 years and older were eligible for the study if they initiated oral bisphosphonate (alendronate, ibandronate, or risedronate) therapy from January 1, 2001, through December 31, 2009 (index date is date of first oral bisphosphonate claim) and were continuously enrolled with medical and pharmacy benefits for 1 year before (baseline period) and 1 year after (follow-up period) the index date.

Patients were excluded if they had Paget's disease or a malignant neoplasm during the baseline or follow-up period or had claims for 2 oral osteoporosis therapies on the index date.

\section{Measures}

Patient characteristics assessed on the index date or during the baseline period included age (as of index date); comorbid conditions (celiac disease, chronic kidney disease, depres- sion, diabetes, fatigue, GI mucositis and urination problems, hyperparathyroidism, hypertension, inflammatory bowel disease, inflammatory joint disease, or vitamin D deficiency); Deyo-Charlson Comorbidity Index (CCI) $;^{28}$ and medication use (estrogen, gastroprotective agents, glucocorticoid, and nonsteroidal anti-inflammatory drugs [NSAIDs]). Osteoporosisrelated fractures (i.e., fragility fractures) were defined based on ICD-9-CM codes in the primary or secondary position from all medical and inpatient claims. Fractures of the hip (femur neck), vertebra, as well as nonvertebral fractures (pelvis, humerus, forearm, other femoral sites, tibia, fibula, rib, clavicle, scapula, and trunk) were included. The ICD-9-CM codes used to identify osteoporotic fractures are described in the Appendix. Fractures of hand, skull, digits, feet and ankle, and any open fractures were not considered as osteoporosisrelated fractures. ${ }^{29}$ Fractures of the same site were defined as distinct fractures if the occurrences were at least 30 days apart.

The occurrence of GI events was assessed during the baseline period and at 3, 6, and 12 months of follow-up (i.e., post-treatment). GI events and their severity classification were defined by the presence of relevant ICD-9-CM codes in the primary and/or secondary position from all medical or inpatient claims. The list of GI events, encompassing minor symptoms such as heartburn and nausea through major acute conditions such as GI hemorrhage and ulcers, is shown in the Appendix. Certain ICD-9-CM codes, typically those involving hemorrhage or perforation, were classified as serious GI events. The proportion of patients with GI events was defined as the percentage of individuals having at least 1 GI event and was calculated at baseline and at 3, 6, and 12 months in the follow-up period.

Treatment patterns assessed during follow-up were persistence, discontinuation, switching, and augmentation. Persistence was defined as continuous refills of the index drug class, without additional drug therapy from a different drug class, from the index date until the end of the follow-up period with no gaps in days supply greater than 45 days. The use of 45 days as the allowable gap was determined based on the fact that a typical prescription of oral bisphosphonate is usually 30 days, and we allowed a "leeway" of up to 1.5 times the typical duration of a prescription refill. Discontinuation was defined as the first gap in supply greater than 45 days at any time from the index date to the end of the follow-up period.

Switching was defined as a change in the index drug class, that is, from a bisphosphonate to a nonbisphosphonate, with discontinuation of the index drug class. For example, a medication change from ibandronate to raloxifene was considered a switch because these drugs represent different classes, while a medication change from alendronate to ibandronate was not considered a switch because both are within the bisphosphonate class.

Augmentation was defined as a new drug prescription for a nonindex drug class being observed while the index drug class 


\section{FIGURE 1 Patient Selection}

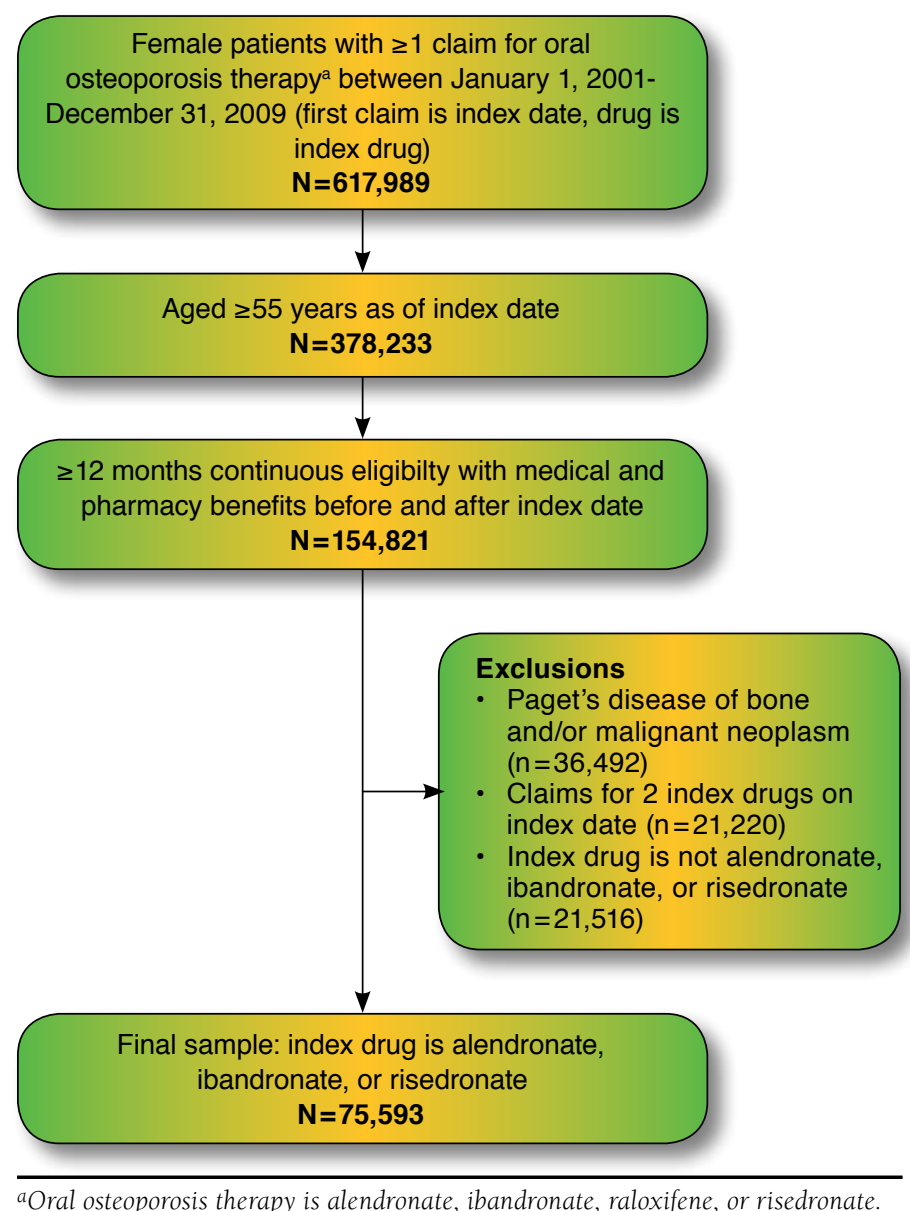

a Oral osteoporosis therapy is alendronate, ibandronate, raloxifene, or risedronate.

was still being refilled. If a patient exhibited multiple treatment patterns (e.g., first switching, then augmenting), the first exhibited pattern was used to define their treatment pattern status for the study. All forms of osteoporosis therapy (oral, injectable, intranasal, and intravenous) were considered in the definition of switching and augmentation, including bisphosphonates (alendronate, ibandronate, risedronate, and zoledronic acid), calcitonin, denosumab, raloxifene, and teriparatide.

\section{Statistical Analysis}

Baseline characteristics were assessed and compared between patients with and without post-treatment GI events. Differences in baseline characteristics were evaluated using t-tests for continuous variables and chi-square tests for binary and categorical variables.

The association between post-treatment GI events and treatment discontinuation or switching during 12-month follow-up was examined and quantified using Cox regression. In the regression model, the study outcome was time to discontinu- ation or switch, right censored at end of the 12-month followup. The independent variable of interest was a time-varying variable indicating the occurrence of a post-treatment GI event, censored at discontinuation or switching. Because the patients with baseline GI events could be more prone to posttreatment GI diagnoses than those without baseline GI events, the regression model was developed by stratifying the presence of baseline GI events. Furthermore, the model also included age (grouped as 55-59, 60-69, 70-79, and 80-89), CCI, and the following baseline clinical characteristics expressed as binary variables (presence or absence): comorbid conditions, medication use, and osteoporosis-related fracture, as control variables. In addition, sensitivity analyses were conducted to assess the association for the occurrence of post-treatment GI events within 3 and 6 months before the discontinuation and/or switching. Augmenters were excluded from the regression analysis as only $189(0.3 \%)$ patients in the study were taking 2 osteoporosis medications simultaneously.

\section{Results}

\section{Patient Selection and Baseline Characteristics}

A total of 617,989 women with at least 1 claim for an oral osteoporosis therapy during the index window January 1 , 2002-December 31, 2009, were identified, and the final sample included 75,593 eligible patients (Figure 1). The predominant reasons for exclusion were aged less than 55 years as of the index date $(n=239,756,38.8 \%)$ and lack of continuous eligibility with medical and pharmacy benefits during baseline and follow-up $(n=223,412,36.2 \%)$. Mean age at index was 64.4 years (Table 1). GI events were diagnosed in $26.6 \%$ of the patients in the baseline period, and $3.6 \%$ of patients had a serious baseline GI event. There were 4,531 (6.0\%) patients with an osteoporotic fracture, and $17.9 \%$ of patients used gastroprotective agents. There were several differences in the baseline characteristics among patients who did versus those who did not experience a post-treatment GI event, most notably a higher rate of baseline GI events in patients who subsequently had a post-treatment GI event (48.6\% vs. $18.0 \%$ ). A higher proportion of patients who experienced a post-treatment GI event also had an osteoporotic fracture (7.4\% vs. 5.4\%), used gastroprotective agents (34.3\% vs. $11.5 \%$ ), and had osteoporosisrelated comorbidities during baseline.

\section{Rate of GI Events}

For all patients, the rate of GI events at 3, 6, and 12 months post-treatment was $10.7 \%, 17.5 \%$, and $28.0 \%$, respectively (Table 2). Compared with patients who did not experience a baseline GI event (73.4\% of patients), patients with a baseline GI event (26.6\% of patients) had a higher rate of GI events during the post-treatment period: $23.0 \%$ vs. $6.3 \%$ during the first 3 months post-treatment, $35.3 \%$ vs. $11.1 \%$ at 6 months, and $51.2 \%$ vs. $19.6 \%$ at 12 months. 


\section{Association Between Gastrointestinal Events and Persistence with Osteoporosis Therapy: Analysis of Administrative Claims of a U.S. Managed Care Population}

\section{TABLE 1 Baseline Patient Characteristics}

\begin{tabular}{|c|c|c|c|c|}
\hline Characteristics & All Patients $(N=75,593)$ & $\begin{array}{l}\text { With Post-Treatment GI } \\
\text { Event }(n=21,142)\end{array}$ & $\begin{array}{l}\text { Without Post-Treatment } \\
\text { GI Event }(\mathrm{n}=54,451)\end{array}$ & $P$ Value ${ }^{a}$ \\
\hline Index age in years, mean (SD) & $\begin{array}{|ll|}64.4 \quad(8.4) \\
\end{array}$ & $64.9 \quad(8.5)$ & $64.3 \quad(8.4)$ & $<0.001$ \\
\hline \multicolumn{4}{|l|}{ Age group, n (\%) } & $<0.001$ \\
\hline $55-59$ & $27,820(36.8)$ & $7,267(34.4)$ & $20,553(37.8)$ & - \\
\hline $60-69$ & $28,770(38.1)$ & $8,223(38.9)$ & $20,547(37.7)$ & - \\
\hline $70-79$ & $12,038(15.9)$ & $3,558(16.8)$ & $8,480(15.6)$ & - \\
\hline$\geq 80$ & $6,965 \quad(9.2)$ & $2,094 \quad(9.9)$ & $4,871 \quad(9.0)$ & - \\
\hline GI event, $n(\%)$ & $20,073(26.6)$ & $10,276(48.6)$ & $9,797(18.0)$ & $<0.001$ \\
\hline Serious GI event, $\mathbf{n}(\%)$ & $2,707 \quad(3.6)$ & $1,380 \quad(6.5)$ & $1,327 \quad(2.4)$ & $<0.001$ \\
\hline Osteoporosis-related fracture, n (\%) & $4,531 \quad(6.0)$ & $1,568 \quad(7.4)$ & 2,963 & $<0.001$ \\
\hline Hip & $(1.3)$ & $331 \quad(1.6)$ & $(1.2)$ & $<0.001$ \\
\hline Vertebral & $1,677 \quad(2.2)$ & (3.1) & 1,025 & $<0.001$ \\
\hline Nonvertebral & $2,574 \quad(3.4)$ & $(4.0)$ & $1,719 \quad(3.2)$ & $<0.001$ \\
\hline \multicolumn{4}{|l|}{ Number of distinct fracture sites, $n(\%)$} & $<0.001$ \\
\hline 1 & $3,876 \quad(5.1)$ & $1,319 \quad(6.2)$ & $2,557 \quad(4.7)$ & - \\
\hline 2 & $612 \quad(0.8)$ & $228 \quad(1.1)$ & $384 \quad(0.7)$ & - \\
\hline 3 & $43 \quad(0.1)$ & $21 \quad(0.1)$ & $(0.0)$ & - \\
\hline \multicolumn{5}{|l|}{ Medication use, $\mathrm{n}(\%)$} \\
\hline Gastroprotective agents & $13,523(17.9)$ & $7,254(34.3)$ & $6,269(11.5)$ & $<0.001$ \\
\hline Proton pump inhibitor & $11,222(14.9)$ & $6,279(29.7)$ & $4,943 \quad(9.1)$ & $<0.001$ \\
\hline $\mathrm{H} 2$ receptor antagonist & $2,596 \quad(3.4)$ & $1,243 \quad(5.9)$ & $1,353 \quad(2.5)$ & $<0.001$ \\
\hline Cytoprotective agent & $790 \quad(1.1)$ & $399 \quad(1.9)$ & $391 \quad(0.7)$ & $<0.001$ \\
\hline NSAIDs & $18,985(25.1)$ & $6,539(30.9)$ & $12,446(22.9)$ & $<0.001$ \\
\hline Glucocorticoids & $13,094 \quad(17.3)$ & $4,679(22.1)$ & $8,415(15.5)$ & $<0.001$ \\
\hline Estrogen & $16,116(21.3)$ & $4,700(22.2)$ & $11,416(21.0)$ & $<0.001$ \\
\hline Charlson Comorbidity Index, mean (SD) & $0.56 \quad(1.0)$ & $0.8 \quad(1.2)$ & $0.5 \quad(0.9)$ & $<0.001$ \\
\hline \multicolumn{5}{|c|}{ Common osteoporosis-related comorbidities, $\mathbf{n}(\%)$} \\
\hline Chronic inflammatory bowel disease & $679 \quad(0.9)$ & $318 \quad(1.5)$ & $361 \quad(0.7)$ & $<0.001$ \\
\hline Chronic inflammatory joint disease & $15,586(20.6)$ & $5,751 \quad(27.2)$ & $9,835(18.1)$ & $<0.001$ \\
\hline Celiac disease & $246 \quad(0.3)$ & $113 \quad(0.5)$ & $133 \quad(0.2)$ & $<0.001$ \\
\hline Diabetes & $8,093(10.7)$ & $2,673(12.6)$ & $5,420(10.0)$ & $<0.001$ \\
\hline Depression & $4,584 \quad(6.1)$ & $1,818 \quad(8.6)$ & $2,766 \quad(5.1)$ & $<0.001$ \\
\hline Renal failure & $778 \quad(1.0)$ & $335 \quad(1.6)$ & $443 \quad(0.8)$ & $<0.001$ \\
\hline Hypertension & $32,751 \quad(43.3)$ & $10,575(50.0)$ & $22,176(40.7)$ & $<0.001$ \\
\hline GI mucositis and/or urination problems & $5,649 \quad(7.5)$ & $2,205(10.4)$ & $3,444 \quad(6.3)$ & $<0.001$ \\
\hline Vitamin D deficiency & $662 \quad(0.9)$ & $225 \quad(1.1)$ & $437 \quad(0.8)$ & 0.001 \\
\hline Fatigue & $12,203(16.1)$ & $4,471 \quad(21.2)$ & $7,732(14.2)$ & $<0.001$ \\
\hline
\end{tabular}

\section{Osteoporosis Treatment Patterns}

Discontinuation rate was high in this patient population, observed in 45,310 (59.9\%) patients (Table 3). Only 39.3\% of patients were persistent with osteoporosis therapy. Switching and augmentation of therapy occurred in $400(0.5 \%)$ and 189 (0.3\%) patients, respectively. Among patients with a baseline GI event, $65.0 \%$ discontinued treatment; $34.2 \%$ were persistent with treatment; $0.6 \%$ switched to a new osteoporosis drug class treatment; and $0.3 \%$ augmented treatment. Among patients with a post-treatment GI event, $67.1 \%$ discontinued; 31.9\% were persistent; $0.8 \%$ switched; and $0.3 \%$ augmented treatment. The mean time from treatment initiation to treatment

\section{TABLE 2 Rate of Gl Events Post-Treatment}

Occurrence of GI Events Post-Treatment

\begin{tabular}{|c|c|c|c|}
\hline & \\
\hline & 3 Months & 6 Months & 12 Months \\
\hline & n $\quad(\%)$ & n $\quad(\%)$ & n $\quad(\%)$ \\
\hline All patients $(\mathrm{N}=75,593)$ & $8,087(10.7)$ & $13,217 \quad(17.5)$ & $21,142(28.0)$ \\
\hline $\begin{array}{l}\text { Patients without baseline } \\
\text { GI event }(n=55,520)\end{array}$ & $3,478 \quad(6.3)$ & $6,141 \quad(11.1)$ & $10,866(19.6)$ \\
\hline $\begin{array}{l}\text { Patients with baseline } \\
\text { GI event }(n=20,073)\end{array}$ & $4,609(23.0)$ & $7,076(35.3)$ & $10,276(51.2)$ \\
\hline
\end{tabular}




\section{Association Between Gastrointestinal Events and Persistence with Osteoporosis Therapy: Analysis of Administrative Claims of a U.S. Managed Care Population}

Distribution of Gl Events and Mean Time to Discontinuation, Switching, or Augmentation of Therapy

\begin{tabular}{|c|c|c|c|c|c|}
\hline & All Patients & Persistence & Discontinue & Switch & Augment \\
\hline & $(\%)$ & $(\%)$ & $(\%)$ & n $\quad(\%)$ & n $\quad(\%)$ \\
\hline All patients $(\mathrm{N}=75,593)^{\mathrm{a}}$ & $75,593(100.0)$ & $29,694 \quad(39.3)$ & $45,310 \quad(59.9)$ & $(0.5)$ & 189 \\
\hline $\begin{array}{l}\text { Patients with baseline GI event }{ }^{b} \\
\text { (\% of all patients, } n=20,073)\end{array}$ & $20,073(100.0)$ & $6,863 \quad(34.2)$ & $13,043 \quad(65.0)$ & $(0.6)$ & $(0.3)$ \\
\hline $\begin{array}{l}\text { Patients with post-treatment GI event during } \\
0-12 \text { months follow-upc }\end{array}$ & $21,142(100.0)$ & $6,739 \quad(31.9)$ & $14,186 \quad(67.1)$ & $(0.8)$ & $(0.3)$ \\
\hline $\begin{array}{l}\text { Patients with post-treatment GI event during } \\
0-6 \text { months follow-upc }\end{array}$ & $13,217(100.0)$ & $4,067 \quad(30.8)$ & $9,004 \quad(68.1)$ & $(0.8)$ & $(0.3)$ \\
\hline \multirow{2}{*}{$\begin{array}{l}\text { Patients with post-treatment GI event during } \\
0-3 \text { months follow-upc }\end{array}$} & $8,087(100.0)$ & $2,448 \quad(30.3)$ & $5,545 \quad(68.6)$ & $(0.9)$ & $(0.3)$ \\
\hline & & & Mean (SD) & Mean (SD) & Mean (SD) \\
\hline $\begin{array}{l}\text { Days from treatment initiation until discontinuation, } \\
\text { switching, or augmentation }\end{array}$ & - & - & $115.6 \quad(98.4)$ & $103.3(94.4)$ & $102.7(107.3)$ \\
\hline \multicolumn{6}{|c|}{$\begin{array}{l}{ }^{a} \text { Distribution of patients by treatment pattern cohort as a percentage of all patients }(N=75,593) . \\
b \text { Distribution of patients by treatment pattern cohort expressed as a percentage of all patients with a baseline GI event }(n=20,073) . \\
\text { cDistribution of patients by treatment pattern cohort expressed as a percentage of all patients with a post-treatment GI event }(0-12 \text { months, } n=21,142 ; 0-6 \text { months, } \\
n=13,217 ; 0-3 \text { months, } n=8,087) \text {. } \\
\text { GI = gastrointestinal; } S D=\text { standard deviation. }\end{array}$} \\
\hline
\end{tabular}

discontinuation was 115.6 days, 103.3 days from treatment initiation to switching treatment, and 102.7 days from treatment initiation to augmenting treatment.

\section{Association Between GI Events and Osteoporosis Treatment Persistence}

The results of the Cox regression model for the association between post-treatment GI events and the likelihood of discontinuation or switching are shown in Table 4. Patients with a post-treatment GI event during the 12-month follow-up were $35.6 \%$ more likely to discontinue bisphosphonates or switch to nonbisphosphonates than patients without any post-treatment GI event (hazard ratio $[\mathrm{HR}]=1.356$; 95\% confidence interval $[C I]=1.318-1.396$ ). Advanced age (age categories 70-79 and 80-89) increased the risk of discontinuing or switching therapy by $4.2 \%-6.4 \%$, and higher baseline CCI scores increased the risk by $3.1 \%$. A baseline osteoporosis-related fracture decreased the risk of discontinuation or switching by $5.1 \%$. Baseline use of NSAIDS or glucocorticoids was associated with a $4.8 \%-7.6 \%$ higher risk of discontinuation or switching.

The association of a post-treatment GI event with discontinuation or switching was stronger when it occurred within 3 or 6 months before treatment discontinuation or switching. In the sensitivity analysis, a post-treatment GI event within 6 months before treatment discontinuation or switching was associated with $37.9 \%$ greater likelihood of discontinuation or switching ( $\mathrm{HR}=1.379,95 \% \mathrm{CI}=1.338-1.421)$. A post-treatment GI event within 3 months of treatment discontinuation or switching was associated with $45.6 \%$ greater risk of discontinuation or switching ( $\mathrm{HR}=1.456,95 \% \mathrm{CI}=1.408-1.505)$. Estimated effects for other patient characteristics were similar in the 3-month, 6-month, and 12-month analyses.

\section{Discussion}

A majority of patients (59.9\%) initiating bisphosphonate treatment discontinued therapy in the first year. Most patients who discontinued therapy did so within the first 3 months after treatment initiation. GI events that occurred after treatment initiation were associated with a $36 \%$ greater risk of discontinuing bisphosphonate or switching to nonbisphosphonate therapy. The sooner the GI event occurred after initiating treatment, the greater was the risk of discontinuation or switching.

The observed association between GI events and decreased osteoporosis treatment persistence is supported by previous work. In a prospective study of postmenopausal women in the United States, new and continuing users of osteoporosis medication (primarily oral bisphosphonates) who reported any GI side effects at study entry had 39\% greater odds of discontinuing therapy by month 6 of the study. ${ }^{27} \mathrm{~A}$ retrospective analysis of patients in California reported that a GI diagnosis in the year prior to initiating alendronate was associated with a $21 \%$ lower odds of being persistent in the following year. ${ }^{19}$ Similarly, a history of upper GI problems in the year prior to starting bisphosphonate therapy was associated with $7 \%$ lower likelihood of being persistent with therapy in United Kingdom patients. ${ }^{17}$ Our study adds to the literature on the association between GI events and bisphosphonate discontinuation or switching; we accounted not only for a history of GI events through stratification in the Cox regression model, but we also examined GI events that occurred after bisphosphonate treatment initiation. No causal relationship between use of oral bisphosphonates and occurrence of GI events after initiation of oral bisphosphonates was established in this study. The occurrence of GI events after initiation of oral bisphosphonates 


\begin{tabular}{|c|c|c|c|c|c|c|c|c|c|}
\hline & \multirow{2}{*}{\multicolumn{3}{|c|}{$\begin{array}{c}\text { Main Analysis }{ }^{\mathrm{a}} \\
12 \text { Months }^{\mathrm{b}}\end{array}$}} & \multicolumn{6}{|c|}{ Sensitivity Analysis ${ }^{a}$} \\
\hline & & & & \multicolumn{3}{|c|}{6 Months $^{c}$} & \multicolumn{3}{|c|}{3 Months ${ }^{\mathrm{d}}$} \\
\hline & HR & $95 \%$ CI & $P$ Value & HR & $95 \%$ CI & $P$ Value & HR & $95 \%$ CI & $P$ Value \\
\hline $\begin{array}{l}\text { Post-treatment GI event before } \\
\text { discontinuation or switching }\end{array}$ & 1.356 & $(1.318,1.396)$ & $<0.0001$ & 1.379 & $(1.338,1.421)$ & $<0.0001$ & 1.456 & $(1.408,1.505)$ & $<0.0001$ \\
\hline Age group (reference: 55-59) & & & $<0.0001$ & & & $<0.0001$ & & & $<0.0001$ \\
\hline $60-69$ & 0.972 & $(0.951,0.993)$ & & 0.972 & $(0.951,0.993)$ & & 0.973 & $(0.952,0.994)$ & \\
\hline $70-79$ & 1.064 & $(1.035,1.095)$ & & 1.064 & $(1.035,1.094)$ & & 1.064 & $(1.035,1.095)$ & \\
\hline $80-89$ & 1.042 & $(1.006,1.078)$ & & 1.042 & $(1.006,1.078)$ & & 1.042 & $(1.007,1.079)$ & \\
\hline Baseline osteoporosis-related fractures & 0.949 & $(0.932,0.967)$ & $<0.0001$ & 0.950 & $(0.932,0.967)$ & $<0.0001$ & 0.950 & $(0.932,0.968)$ & $<0.0001$ \\
\hline \multicolumn{10}{|l|}{ Baseline medication use } \\
\hline Gastroprotective agents & 0.991 & $(0.965,1.017)$ & 0.4878 & 0.994 & $(0.969,1.021)$ & 0.6775 & 0.998 & $(0.972,1.024)$ & 0.8696 \\
\hline NSAIDs & 1.048 & $(1.025,1.071)$ & $<0.0001$ & 1.048 & $(1.025,1.071)$ & $<0.0001$ & 1.048 & $(1.025,1.072)$ & $<0.0001$ \\
\hline Glucocorticoids & 1.076 & $(1.050,1.103)$ & $<0.0001$ & 1.076 & $(1.050,1.103)$ & $<0.0001$ & 1.077 & $(1.050,1.104)$ & $<0.0001$ \\
\hline Estrogen & 0.840 & $(0.821,0.860)$ & $<0.0001$ & 0.840 & $(0.821,0.860)$ & $<0.0001$ & 0.840 & $(0.821,0.860)$ & $<0.0001$ \\
\hline Charlson Comorbidity Index score & 1.031 & $(1.019,1.043)$ & $<0.0001$ & 1.031 & $(1.019,1.043)$ & $<0.0001$ & 1.032 & $(1.020,1.044)$ & $<0.0001$ \\
\hline Inflammatory bowel disease & 0.948 & $(0.861,1.044)$ & 0.2809 & 0.948 & $(0.861,1.044)$ & 0.2791 & 0.949 & $(0.861,1.044)$ & 0.2824 \\
\hline Inflammatory joint disease & 1.048 & $(1.023,1.073)$ & 0.0001 & 1.048 & $(1.024,1.074)$ & $<0.0001$ & 1.049 & $(1.025,1.074)$ & $<0.0001$ \\
\hline Celiac disease & 0.938 & $(0.799,1.100)$ & 0.4304 & 0.939 & $(0.800,1.103)$ & 0.4442 & 0.941 & $(0.801,1.104)$ & 0.4534 \\
\hline Diabetes & 1.097 & $(1.059,1.135)$ & $<0.0001$ & 1.096 & $(1.059,1.135)$ & $<0.0001$ & 1.096 & $(1.058,1.135)$ & $<0.0001$ \\
\hline Depression & 1.110 & $(1.070,1.152)$ & $<0.0001$ & 1.111 & $(1.071,1.153)$ & $<0.0001$ & 1.112 & $(1.071,1.154)$ & $<0.0001$ \\
\hline Chronic kidney disease & 0.982 & $(0.895,1.077)$ & 0.6990 & 0.980 & $(0.894,1.075)$ & 0.6672 & 0.979 & $(0.893,1.073)$ & 0.6473 \\
\hline Hypertension & 1.075 & $(1.054,1.096)$ & $<0.0001$ & 1.075 & $(1.054,1.096)$ & $<0.0001$ & 1.075 & $(1.054,1.097)$ & $<0.0001$ \\
\hline GI mucositis and urination problems & 1.036 & $(1.001,1.072)$ & 0.0432 & 1.036 & $(1.001,1.072)$ & 0.0417 & 1.037 & $(1.002,1.073)$ & 0.0396 \\
\hline Hyperparathyroidism & 1.011 & $(0.908,1.126)$ & 0.8404 & 1.011 & $(0.908,1.125)$ & 0.848 & 1.012 & $(0.909,1.126)$ & 0.8335 \\
\hline Vitamin D deficiency & 1.082 & $(0.985,1.190)$ & 0.1018 & 1.082 & $(0.984,1.189)$ & 0.104 & 1.082 & $(0.984,1.189)$ & 0.1027 \\
\hline Fatigue & 1.101 & $(1.075,1.129)$ & $<0.0001$ & 1.102 & $(1.075,1.130)$ & $<0.0001$ & 1.103 & $(1.076,1.131)$ & $<0.0001$ \\
\hline \multicolumn{10}{|c|}{$\begin{array}{l}\text { aAll models included stratification by the presencelabsence of baseline GI events and the baseline GI event severity classification. } \\
\text { bPost-treatment GI event occurred within } 12 \text { months of discontinuation or switch; 75,593 observations; pseudo } R^{2}=0.0179 \text {. } \\
\text { cPost-treatment GI event occurred within } 6 \text { months of discontinuation or switch; 75,593 observations; pseudo } R^{2}=0.0179 \text {. } \\
\text { dPost-treatment GI event occurred within } 3 \text { months of discontinuation or switch; 75,593 observations; pseudo } R^{2}=0.0184 \text {. } \\
\text { CI= confidence interval; GI=gastrointestinal; HR=hazard ratio; NSAID = nonsteroidal anti-inflammatory drug. }\end{array}$} \\
\hline
\end{tabular}

may be associated with use of oral bisphosphonates, a common underlying condition, or concomitant treatment, such as NSAIDs or corticosteroids, that would either independently cause or predispose patients to GI problems. The sensitivity analyses for GI events that occurred within 3 and 6 months of treatment discontinuation or switching supported not only the main findings at 12 months but also established a link between the proximity of the post-treatment GI event and likelihood of treatment discontinuation or switching.

These results have important clinical implications for osteoporosis treatment in patients with a history of GI events and those who experience GI events post-treatment. Among patients with a GI event within 1 year prior to treatment initiation, 51.2\% experienced a GI event during the first 12 months post-treatment, compared with only $19.6 \%$ of patients without a pretreatment GI event. Thus, patients with a history of GI events are at an increased risk for experiencing GI events during osteoporosis treatment. We also observed in the sensitivity analysis that the more recent a GI diagnosis, the stronger its effect on treatment discontinuation or switching. Even though GI events with relatively less severity, such as abdominal pains, may not lead to discontinuation or switching, patients who experienced any GI events after bisphosphonate treatment initiation had significantly greater likelihood of discontinuation or switching. In the main analysis, a post-treatment GI diagnosis increased the likelihood of discontinuation or switching by $35.6 \%$. The association was strengthened when considering only those post-treatment GI diagnoses that occurred within 6 months before discontinuation/switching $(\mathrm{HR}=1.379)$ and the post-treatment GI events that occurred within 3 months $(H R=1.456)$. This finding further reinforces the clinical implication that the decision to discontinue or switch treatment can be significantly influenced by the presence of GI events after initiation of osteoporosis treatment, especially for patients with a history of GI problems. No causal relationship between occurrence of GI events and discontinuation or switching of 


\section{Association Between Gastrointestinal Events and Persistence with Osteoporosis Therapy: Analysis of Administrative Claims of a U.S. Managed Care Population}

treatment was established in this study. There are unobserved external factors that can impact this association and were not accounted for in our regression model.

The predominant treatment pattern in this study was discontinuation of therapy: $59.9 \%$ of patients discontinued bisphosphonate in the first 12 months of treatment, and the mean time to discontinuation occurred soon (115.6 days) after treatment initiation. In previous database studies in the United States and Europe, 17\%-58\% of patients were persistent with bisphosphonate therapy during the first year of treatment, and our mean persistence rate $(39.3 \%)$ is within this range. ${ }^{17-19,21,30}$ The wide range in previously reported studies is likely a function of differences in study methodology, oral bisphosphonate dosing schedule (e.g., daily vs. weekly), and patient characteristics (e.g., men vs. women). For example, we used a medication supply gap of 45 days or less to define persistence, and the supply gap in earlier studies ranged from 30-183 days, with larger gaps typically resulting in greater persistence rates. ${ }^{18-20}$

Nonpersistence with osteoporosis therapy is associated with greater fracture risk, ${ }^{10,17,20}$ and efforts to improve persistence are essential to avoid adverse clinical outcomes and their attendant health care costs. Our results suggest a strong link between post-treatment GI events and decreased bisphosphonate treatment persistence in the first year of therapy. The management of osteoporosis patients should include screening of patients with comorbid GI conditions prior to bisphosphonate initiation and proactive follow-up monitoring of GI complaints to improve medication persistence.

\section{Limitations}

This study had several limitations, and the results should be considered in this context. The treatment patterns we observed are based on the allowed refill gap of 45 days and may vary depending on the length of the gap considered. The total number of patients with GI events may have been underestimated because only GI events that resulted in a medical service claim were included in this analysis. GI events that did not result in a medical claim may have also influenced the risk for discontinuation and switching, but these events were not accounted for. We only examined the first change in treatment pattern (i.e., augmentation, discontinuation, or switching); it is possible that some patients re-initiated the same or a different osteoporosis therapy during the study interval. The regression model for risk of discontinuation or switching accounted for several patient demographic and clinical characteristics, but there may have been other unidentified or unmeasured factors that influenced the risk of discontinuation or switching. For example, we did not measure the presence of bone mineral density testing at baseline, which has been associated with higher rates of compliance with bisphosphonate therapy. ${ }^{31,32}$ Augmenters are excluded in the regression analysis, since augmenters are not as clinically meaningful as patients with the other treatment patterns. It is not common for a patient to take 2 different bisphosphonates or 2 different nonbisphosphonates at the same time. The regression analysis for post-treatment GI events and treatment discontinuation or switching represents an association only and cannot be interpreted to establish causality. Different bisphosphonate dosing frequencies and formulations were not differentiated in the study and may also have influenced treatment patterns. Finally, inclusion required 24 months of continuous health care coverage with medical and pharmacy benefits; thus, the results are primarily applicable to a stable managed care population.

\section{Conclusions}

A large proportion (59.9\%) of patients receiving bisphosphonate treatment did not persist with treatment during the 12-month follow-up period. Among patients on bisphosphonate therapy, $28 \%$ experienced a GI event within a year. Patients who experienced GI events after receiving osteoporosis treatment had increased likelihood of discontinuation or switching by 35.6\%. Treatment discontinuation may lead to diminished treatment outcomes and higher health care utilization, causing a burden associated with post-treatment GI events. These findings suggest that post-treatment GI events negatively impact persistence to osteoporosis medication. Clinical management of patients taking bisphosphonate medication should recognize the potential for post-treatment GI events to increase the risk of bisphosphonate treatment discontinuation or switching. Future studies should evaluate the association of nonpersistence as a result of GI events with health care resource use. For osteoporotic patients with GI events, physicians should be cautious to initiate their osteoporosis treatment with oral bisphosphonates, since patients with a history of GI events could have a higher risk of developing subsequent GI events, and occurrence of GI events are associated with treatment discontinuation or switching. Osteoporosis management programs may be considered to improve persistence among patients with osteoporosis.

\section{Authors}

ANKITA MODI, PhD, is Director, and SHIVA SAJJAN, PhD, is Director, Center for Observational and Real-World Evidence, Merck E Co., Inc., Kenilworth, New Jersey. E. S. SIRIS, MD, is Professor, Columbia University Medical Center, New York, New York; XIAOQIN YANG, PhD, is a Fellow in the Merck Center for Observational and Real-World Evidence fellowship program in partnership with Temple University School of Pharmacy, Philadelphia, Pennsylvania; and CHUN-PO STEVE FAN, PhD, is Director, Asclepius JT, New York, New York.

AUTHOR CORRESPONDENCE: Ankita Modi, PhD, Merck \& Co., Inc., 600 Corporate Dr., Lebanon, NJ 08833. Tel.: 908.236.4563; Fax: 908.236.4697; E-mail: ankita.modi@merck.com. 


\section{Association Between Gastrointestinal Events and Persistence with Osteoporosis Therapy: Analysis of Administrative Claims of a U.S. Managed Care Population}

\section{DISCLOSURES}

This study was sponsored by Merck \& Co., Inc. Modi and Sajjan are employees of Merck \& Co., Inc. Yang is a Fellow in the Merck Center for Observational and Real-World Evidence fellowship program in partnership with Temple University. Siris has done consulting for Amgen, Eli Lilly, Merck, Novartis, AgNovos, and Radius. Fan served as a paid consultant by Merck \& Co., Inc., in connection with this study and development of the manuscript.

Study concept was designed primarily by Modi, with assistance from Siris, Sajjan, Fan, and Yang. Data collection was conducted by Sajjan, Fan, and Modi, with assistance from Yang, and analysis was performed by Modi and Sajjan, with assistance from the other authors. The manuscript was written by Yang, Siris, Modi, Sajjan, and Fan, and revised by Modi, Yang, and Fan, with help from Siris and Sajjan.

\section{ACKNOWLEDGMENTS}

Medical writing support was provided by Optum (Eden Prairie, MN) and was funded by Merck \& Co., Inc.

\section{REFERENCES}

1. Wright NC, Looker AC, Saag KG, et al. The recent prevalence of osteoporosis and low bone mass in the United States based on bone mineral density at the femoral neck or lumbar spine. J Bone Miner Res. 2014;29(11):2520-26. 2. Office of the Surgeon General. Bone health and osteoporosis: a report of the Surgeon General. 2004. Rockville, MD. Available at: http://www.ncbi. nlm.nih.gov/books/NBK45515/. Accessed March 31, 2015.

3. National Osteoporosis Foundation. Clinician's guide to prevention and treatment of osteoporosis. 2014 Issue, Version 1. April 1, 2014. Available at: http://nof.org/files/nof/public/content/file/2791/upload/919.pdf. Accessed March 31, 2015.

4. U.S. Food and Drug Administration. Background document for meeting of Advisory Committee for Reproductive Health Drugs and Drug Safety and Risk Management Advisory Committee. September 9, 2011.

Available at: http://www.fda.gov/downloads/AdvisoryCommittees/ CommitteesMeetingMaterials/drugs/DrugSafetyandRiskManagement AdvisoryCommittee/ucm270958.pdf. Accessed March 31, 2015.

5. Silverman SL, Gold DT. Compliance and persistence with osteoporosis therapies. Curr Rheumatol Rep. 2008;10(2):118-22.

6. Rabenda V, Hiligsmann M, Reginster JY. Poor adherence to oral bisphosphonate treatment and its consequences: a review of the evidence. Expert Opin Pharmacother. 2009;10(14):2303-15.

7. Halpern R, Becker L, Iqbal SU, Kazis LE, Macarios D, Badamgarav E. The association of adherence to osteoporosis therapies with fracture, all-cause medical costs, and all-cause hospitalizations: a retrospective claims analysis of female health plan enrollees with osteoporosis. J Manag Care Pharm. 2011;17(1):25-39. Available at: http://www.amcp.org/data/jmcp/25-39.pdf.

8. Patrick AR, Brookhart MA, Losina E, et al. The complex relation between bisphosphonate adherence and fracture reduction. J Clin Endocrinol Metab. 2010;95(7):3251-59.

9. Cotté FE, Mercier F, De Pouvourville G. Relationship between compliance and persistence with osteoporosis medications and fracture risk in primary health care in France: a retrospective case-control analysis. Clin Ther. 2008;30(12):2410-22.

10. Siris ES, Harris ST, Rosen CJ, et al. Adherence to bisphosphonate therapy and fracture rates in osteoporotic women: relationship to vertebral and nonvertebral fractures from 2 U.S. claims databases. Mayo Clin Proc. 2006;81(8):1013-22.

11. Huybrechts KF, Ishak KJ, Caro JJ. Assessment of compliance with osteoporosis treatment and its consequences in a managed care population. Bone. 2006;38(6):922-28.

12. Lee S, Glendenning P, Inderjeeth CA. Efficacy, side effects and route of administration are more important than frequency of dosing of anti-osteoporosis treatments in determining patient adherence: a critical review of published articles from 1970 to 2009. Osteoporos Int. 2011;22(3):741-53.
13. Copher R, Buzinec P, Zarotsky V, Kazis L, Iqbal SU, Macarios D. Physician perception of patient adherence compared to patient adherence of osteoporosis medications from pharmacy claims. Curr Med Res Opin. 2010;26(4):777-85.

14. Cramer JA, Gold DT, Silverman SL, Lewiecki EM. A systematic review of persistence and compliance with bisphosphonates for osteoporosis. Osteoporos Int. 2007;18(8):1023-31.

15. van den Boogaard CH, Breekveldt-Postma NS, Borggreve SE, Goettsch WG Herings RM. Persistent bisphosphonate use and the risk of osteoporotic fractures in clinical practice: a database analysis study. Curr Med Res Opin. 2006;22(9):1757-64.

16. Curtis JR, Westfall AO, Cheng H, Delzell E, Saag KG. Risk of hip fracture after bisphosphonate discontinuation: implications for a drug holiday. Osteoporos Int. 2008;19(11):1613-20.

17. Gallagher AM, Rietbrock S, Olson M, van Staa TP. Fracture outcomes related to persistence and compliance with oral bisphosphonates. J Bone Miner Res. 2008;23(10):1569-75.

18. Balasubramanian A, Brookhart MA, Goli V, Critchlow CW Discontinuation and reinitiation patterns of osteoporosis treatment among commercially insured postmenopausal women. Int J Gen Med. 2013;6:839-48.

19. Lo JC, Pressman AR, Omar MA, Ettinger B. Persistence with weekly alendronate therapy among postmenopausal women. Osteoporos Int 2006;17(6):922-28.

20. Rabenda V, Mertens R, Fabri V, et al. Adherence to bisphosphonates therapy and hip fracture risk in osteoporotic women. Osteoporos Int. 2008;19(6):811-18.

21. Ziller V, Kostev K, Kyvernitakis I, Boeckhoff J, Hadji P. Persistence and compliance of medications used in the treatment of osteoporosis-analysis using a large scale, representative, longitudinal German database. Int J Clin Pharmacol Ther. 2012;50(5):315-22.

22. Gold DT, Martin BC, Frytak JR, Amonkar MM, Cosman F. A claims database analysis of persistence with alendronate therapy and fracture risk in post-menopausal women with osteoporosis. Curr Med Res Opin. 2007;23(3):585-94.

23. Siris ES, Selby PL, Saag KG, et al. Impact of osteoporosis treatment adherence on fracture rates in North America and Europe. Am J Med. 2009; 122(2 Suppl):S3-13.

24. Tosteson AN, Grove MR, Hammond CS, et al. Early discontinuation of treatment for osteoporosis. Am J Med. 2003;115(3):209-16.

25. Tosteson AN, Do TP, Wade SW, Anthony MS, Downs RW. Persistence and switching patterns among women with varied osteoporosis medication histories: 12-month results from POSSIBLE US. Osteoporos Int. 2010;21(10):1769-80

26. McHorney CA, Schousboe JT, Cline RR, Weiss TW. The impact of osteoporosis medication beliefs and side-effect experiences on non-adherence to oral bisphosphonates. Curr Med Res Opin. 2007;23(12):3137-52.

27. Woo C, Gao G, Wade S, Hochberg MC. Gastrointestinal side effects in postmenopausal women using osteoporosis therapy: 1-year findings in the POSSIBLE US study. Curr Med Res Opin. 2010;26(4):1003-09.

28. Quan H, Sundararajan V, Halfon P, et al. Coding algorithms for defining comorbidities in ICD-9-CM and ICD-10 administrative data. Med Care. 2005;43(11):1130-39.

29. Diez-Perez A, Adachi JD, Agnusdei D, et al. Treatment failure in osteoporosis. Osteoporos Int. 2012;23(12):2769-74.

30. Downey TW, Foltz SH, Boccuzzi SJ, Omar MA, Kahler KH. Adherence and persistence associated with the pharmacologic treatment of osteoporosis in a managed care setting. South Med J. 2006;99(6):570-75.

31. Blouin J, Dragomir A, Fredette M, Ste-Marie LG, Fernandes JC, Perreault S. Comparison of direct health care costs related to the pharmacological treatment of osteoporosis and to the management of osteoporotic fractures among compliant and noncompliant users of alendronate and risedronate: a population-based study. Osteoporos Int. 2009;20(9):1571-81.

32. Wade SW, Curtis JR, Yu J, et al. Medication adherence and fracture risk among patients on bisphosphonate therapy in a large United States health plan. Bone. 2012;50(4):870-75. 


\section{Association Between Gastrointestinal Events and Persistence with Osteoporosis Therapy: Analysis of Administrative Claims of a U.S. Managed Care Population}

\section{APPENDIX Codes for Gastrointestinal Events and Osteoporotic Fractures}

Codes Used to Identify Gastrointestinal Events

ICD-9-CM Code

456.0

456.1

$530.0 \mathrm{x}$

$530.1 \mathrm{x}$

530.2

530.20

530.21

530.3

530.4

530.5

530.7

530.81

530.82

530.84

530.89

531.xx

Esophageal varices with hemorrhage

Duodenal ulcer, acute with hemorrhage and perforation

Duodenal ulcer, acute without hemorrhage or perforation

Duodenal ulcer, chronic or unspecified with hemorrhage

Duodenal ulcer, chronic or unspecified with perforation

Duodenal ulcer, chronic or unspecified with hemorrhage and perforation

Duodenal ulcer, chronic without hemorrhage or perforation

Duodenal ulcer, unspecified as acute or chronic, w/o hemorrhage or perforation

Peptic ulcer, site NOS

Peptic ulcer, acute with hemorrhage

Peptic ulcer, acute with perforation

Peptic ulcer, acute with perforation and hemorrhage

Peptic ulcer, acute without hemorrhage or perforation

Peptic ulcer, chronic or unspecified with hemorrhage

Peptic ulcer, chronic or unspecified with perforation

Peptic ulcer, chronic or unspecified with hemorrhage and perforation

Peptic ulcer, chronic without hemorrhage or perforation

Peptic ulcer, unspecified as acute or chronic, w/o hemorrhage or perforation

Gastrojejunal ulcer

Gastrojejunal ulcer

Gastrojejunal ulcer 


\section{Association Between Gastrointestinal Events and Persistence with Osteoporosis Therapy: Analysis of Administrative Claims of a U.S. Managed Care Population}

\section{APPENDIX Codes for Gastrointestinal Events and Osteoporotic Fractures (continued)}

\begin{tabular}{|c|c|c|}
\hline \multicolumn{2}{|c|}{ Codes Used to Identify Gastrointestinal Events } & \multirow[b]{2}{*}{ Severity Indicator } \\
\hline ICD-9-CM Code & Description & \\
\hline 534.3 & Gastrojejunal ulcer & \\
\hline $535.0 x$ & Acute gastritis & $\mathrm{X}$ \\
\hline 535.11 & Atrophic gastritis with hemorrhage & \\
\hline 535.21 & Gastric mucosal hypertrophy with hemorrhage & \\
\hline $535.4 x$ & Gastritis NEC & \\
\hline $535.5 x$ & Gastritis/duodenitis, NOS & \\
\hline $535.6 x$ & Duodenitis & \\
\hline 536.2 & Persistent vomiting & \\
\hline 536.8 & Dyspepsia and other specified disorders of function of stomach & \\
\hline 536.9 & Stomach function disorders NOS & \\
\hline 537.4 & Gastric/duodenal fistula & \\
\hline $537.8 x$ & Gastroduodenal disorders NEC & \\
\hline 537.9 & Gastroduodenal disorders NOS & \\
\hline 569.83 & Perforation of intestine & \\
\hline $578 . x x$ & GI hemorrhage & $\mathrm{X}$ \\
\hline $787.0 x$ & Nausea and vomiting & \\
\hline 787.1 & Heartburn & \\
\hline 787.2 & Dysphagia & \\
\hline $789.0 x$ & Abdominal pain & \\
\hline 792.1 & Abnormal stool/occult blood & \\
\hline 793.4 & Abnormal exam GI tract & \\
\hline CPT Code & Description & \\
\hline 43200 & Endoscopy, rigid or flexible; diagnostic, with or without collection of specimen(s) by brushing or washing (se & arate procedure) \\
\hline 43202 & $\begin{array}{l}\text { Esophagoscopy, rigid or flexible; diagnostic, with or without collection of specimen(s) by brushing or washin } \\
\text { with biopsy, single or multiple }\end{array}$ & (separate procedure) \\
\hline 43227 & $\begin{array}{l}\text { Esophagoscopy, rigid or flexible; diagnostic, with or without collection of specimen(s) by brushing or washin } \\
\text { with control of bleeding, any method }\end{array}$ & (separate procedure) \\
\hline 43235 & Endoscopy, rigid or flexible; diagnostic, with or without collection of specimen(s) by brushing or washing (se & arate procedure) \\
\hline 43239 & $\begin{array}{l}\text { Upper GI endoscopy including esophagus, stomach, and either the duodenum and/or jejunum as appropriate } \\
\text { out collection of specimen(s) by brushing }\end{array}$ & diagnostic with or with- \\
\hline 43255 & $\begin{array}{l}\text { Upper GI endoscopy including esophagus, stomach, and either the duodenum and/or jejunum as appropriate } \\
\text { out collection of specimen(s) by brushing or washing (separate procedure), with control of bleeding, any met }\end{array}$ & $\begin{array}{l}\text { diagnostic with or with- } \\
\text { d }\end{array}$ \\
\hline 44602 & Suture of small intestine (enterorrhaphy) for perforated ulcer & \\
\hline 44603 & Suture of small intestine (enterorrhaphy) for perforated ulcer & \\
\hline 44605 & Suture of large intestine (colorrhaphy) for perforated ulcer & \\
\hline 74240 & Radiologic examination, GI tract, upper; with or without delayed film, without KUB & \\
\hline 74241 & Radiologic examination, GI tract, upper; with or without delayed films, with KUB & \\
\hline 74245 & Radiologic examination, GI tract, upper; with small bowel, includes multiple serial films & \\
\hline 74246 & $\begin{array}{l}\text { Radiologic examination, GI tract, upper, air contrast, with specific high density barium, effervescent agent, v } \\
\text { with or without delayed films, with KUB }\end{array}$ & th or without glycagon; \\
\hline 74247 & $\begin{array}{l}\text { Radiologic examination, GI tract, upper, air contrast, with specific high density barium, effervescent agent, v } \\
\text { with or without delayed films, without KUB }\end{array}$ & th or without glycagon; \\
\hline 74249 & $\begin{array}{l}\text { Radiologic examination, GI tract, upper, air contrast, with specific high density barium, effervescent agent, } \\
\text { with small bowel follow-through }\end{array}$ & th or without glycagon; \\
\hline
\end{tabular}


Association Between Gastrointestinal Events and Persistence with Osteoporosis Therapy:

Analysis of Administrative Claims of a U.S. Managed Care Population

\section{APPENDIX Codes for Gastrointestinal Events and Osteoporotic Fractures (continued)}

\section{Codes Used to Identify Osteoporotic Fractures}

Skeletal Site

Vertebral: dorsal and lumbar

Vertebral: other

Hip (femur neck)

Nonvertebral

Nonvertebral

\begin{tabular}{l|l}
\hline Rib & $807 . x$ \\
\hline
\end{tabular}

\begin{tabular}{l|l}
\hline Pelvis & $808 . x$ \\
\hline Trunk & $809 . x$ \\
\hline
\end{tabular}

\begin{tabular}{l|l}
\hline Trunk & $809 . x$ \\
\hline
\end{tabular}

\begin{tabular}{l|l}
\hline Clavicle & $810 . x$ \\
\hline
\end{tabular}

\begin{tabular}{l|l}
\hline Scapula & $811 . x$ \\
\hline
\end{tabular}

\begin{tabular}{l|l}
\hline Humerus & $733.11,812 . x$ \\
\hline Forearm (radius and ulna)
\end{tabular}

\begin{tabular}{|l|l}
\hline Forearm (radius and ulna) & $733.12,813 . x$ \\
\hline
\end{tabular}

\begin{tabular}{l|l}
\hline Lower forearm (carpal) & $814 . x$ \\
\hline
\end{tabular}

\begin{tabular}{l|l}
\hline Femur (other) & $733.15,821 . x$ \\
\hline
\end{tabular}

\begin{tabular}{l|l}
\hline Tibia, fibula & $733.15,821 . x$ \\
\hline
\end{tabular}

National Drug Code Numbers Used to Identify Osteoporosis Medications

\begin{tabular}{l|ll} 
Medication & NDC Number
\end{tabular}

Alendronate, $\quad$ 00006003121, 00006003144, 00006007721, 00006007744, 00006021231, 00006027044, 00006071021, 00006071044,

risedronate, $\quad 00006092531,00006092558,00006093628,00006093631,00006093658,00006093672,00006093682,00006383334$,

ibandronate,

zoledronic acid,

calcitonin,

raloxifene,

teriparatide,

denosumab

00093514001, 00093514056, 00093514101, 00093514156, 00093514256, 00093517120, 00093517144, 00093517219, 000935172220, 00093517244, 00378356601, 00378356701, 00378356822, 00378356893, 00378356899, 00378356922, 00378356993,00378356999 00555071951, 00555071954, 00555072051, 00555072054, 00591003104, 00591007704, 00591317104, 00591317304, 16252059902, 16252059944, 16252060102, 16252060144, 16590049104, 16590071804, 16590071820, 16590071830, 16590099930, 16714063101, 16714063102, 16714063201, 16714063202, 16714063301, 16714063302, 21695090104, 21695090204, 23490917401, 33261055401, 35356059404, 41616063583, 41616063588, 41616063683, 41616063688, 41616063768, 41616063868, 49999050104, 51079094105, $51079094205,54569486600,54569521800,54569539900,54569604700,54569605000,54868385700,54868438400$, $54868446200,54868446201,54868446300,54868548000,54868586000,54868586100,54868586200,55045390801$, 55045391501, 55111058801, 55111058830, 55111058901, 55111058930, 55111059048, 55111059248, 55887051620, 55887051630, $55887051660,55887051682,55887051690,58016061300,58016061304,58016061320,58016061330,58016061360,58016061390$, $58016078800,58016078830,58016078860,58016078890,60429077304,60429077312,60505259201,60505259203,60505259301$, $60505259303,60505259404,60505259602,60505259604,60505259608,63874008901,65862032730,65862032804,65862032904$, 67801032003, 68071079030, 68071079130, 68084032264, 68115075504, 68115079300, 68258301401, 68258598801, 68258598902, 00070449201, 00075130601, 00078014923, 00078031154, 00078031190, 00083648505, 00083649005, 00186160813,00245000835, 00406807403, 00781632079, 35356058301, 49884016111, 54569199400, 54569523400, 54868382700, 54868382701, 54868549900, 60505082306, 55513071001, 55513073001, 00004018523, 00004018682, 00004018809, 00004019109, 12280041203, 16590040003, 35356042303, 54868532200, 54868532201, 54868582300, 55887064103, 00002416502, 00002416507, 00002416530, 00002416534 , $00002416579,12280040230,12280041830,49999045830,54569462800,54868417000,54868417001,55289026630,66105053803$, 00149047001, 00149047101, 00149047103, 00149047201, 00149047204, 00149047501, 00149047701, 00149047801, 00149047803, $00430047015,00430047802,00430097903,16590072104,23490924500,49999044804,54569546200,54868438600$,

$54868467100,54868551800,54868606900,55887068504,66105015703,66105015803,68115068104,00002840001,00002897101$, 00075205053, 54868540600, 00078035084, 00078038725, 00078043561, 00078059061, 35356035101

CPT = Current Procedural Terminology; GI = gastrointestinal; ICD-9-CM=International Classification of Diseases, Ninth Revision, Clinical Modification; NDC= National Drug Code; NEC=not elsewhere classified; NOS= not otherwise specified. 